\title{
REFORMULAR PARA APLICAR NO ESTÁGIO JURÍDICO SUPERVISIONADO: DAS DIRETRIZES CURRICULARES ABSTRATAS ÀS FACETAS CRÍTICAS DA REALIDADE DINÂMICA
}

\section{REFORMULATE TO APPLY IN THE LEGAL SUPERVISED INTERNSHIP: FROM THE ABSTRACT CURRICULUM GUIDELINES TO CRITICAL ASPECTS OF DYNAMIC REALITY}

\author{
Luana Adriano Araújo ${ }^{1}$ \\ Roney Carlos de Carvalho ${ }^{2}$
}

\section{RESUMO}

Analisa-se o Estágio Supervisionado como etapa de formação de um jurista consciente das vicissitudes da sociedade complexa. Avalia-se como o sistema jurídico de ensino erigiu-se, constatando um inicial afastamento da prática, em bipartição entre realidade e teoria. Subsequentemente, perscruta-se a instituição do Estágio Supervisionado nas grades curriculares, cotejando documentos regulatórios atinentes. Identifica-se, dentro da concretização propugnada da atividade, o incremento da formação do estudante, averiguando ainda o papel exercido pelo professor orientador. No mesmo esteio, tendo em vista a aproximação entre práxis e academia, evidencia-se, por fim, a estrutura atual do Núcleo de Práticas Jurídicas da Universidade Federal do Ceará.

Palavras-chave: Núcleo de práticas jurídicas; Estágio supervisionado; Pedagogia e prática

\section{ABSTRACT}

It analyzes the Supervised Internship as a step of composing a jurist aware of the vicissitudes of complex society. It shows how the legal education system was erected, noting an early departure from the practice, splitting reality and theory. Sequently, analyzes the institution of supervised training in the curricula, studing regulatory documents about the subject. Identifies how the advocated activity achievement increases student training, also ascertaining the role played by the teacher advisor. At last, seeking to a rapprochement between practice and academia, highlights, finally, the current structure of the Legal Practice Center of the Federal University of Ceará.

Keywords: Center for legal practice; Supervised internship; Pedagogy and practice

\footnotetext{
${ }^{1}$ Mestranda em Direito e Ordem Jurídica Constitucional pela Universidade Federal do Ceará. Coordenadora da ONG Instituto Verdeluz. Coordenadora do Projeto Arvore-ser. Ceará (Brasil). E-mail: luana.adriano88@gmail.com

2 Mestrando em Direito e Ordem Jurídica Constitucional pela Universidade Federal do Ceará. Assessor Parlamentar na Assembleia Legislativa do Estado do Ceará (Brasil). E-mail: rc.carvalho21@ gmail.com
} 


\section{INTRODUÇÃO}

Tendo em vista a reformulação das diretrizes curriculares tendentes à formação estudantil integral, o Estágio Supervisionado compõe, hodiernamente, como disciplina obrigatória dos cursos jurídicos brasileiros, o processo pelo qual o estudante de direito passa para tornar-se um jurista. Há nesta instituição curricular imperativa a intenção patente de aproximar o discente jurídico da prática, não raro apartada dos conhecimentos adquiridos durante o acompanhamento do curso.

Em virtude da relevância desta temática, analisa-se, neste trabalho de que forma resta articulada, dentro da realidade dos cursos de ensino jurídico brasileiro, a instituição curricular da disciplina de Estágio Supervisionado. Para tanto, aborda-se historicamente o estabelecimento regulamentar dentro da matriz pedagógica jurídica, perscrutando de que maneira a atividade restou considerada no delongar do tempo de modulação e remodulação constantes - dos cursos de ensino jurídico brasileiros.

Ainda, com vistas a estabelecer de que maneira a previsão do estágio curricular obrigatório se justifica teleologicamente, mormente para os envolvidos na cadeia da metodologia pedagógica - quais sejam, o discente e o docente -, tangencia-se de que forma o Estágio Supervisionado contribui para a consecução do perfil esperado do profissional de direito e qual o papel do professor orientador nesta jornada. Por fim, almejando evidenciar com argumentos de ordem discursivo-material, aborda-se a situação do Núcleo de Práticas Jurídicas da Universidade Federal do Ceará, buscando averiguar de que maneira o funcionamento da estrutura contribui para a formação do jurista.

Ressalte-se, a título de informação, que o método utilizado foi o bibliográfico, por meio do levantamento de livros e textos veiculados em obras afetas à temática da metodologia do ensino jurídico. Perscrutou-se, ainda, os textos normativos associados à temática. Ademais, a partir da abordagem analítica de dados fornecidos pela secretaria do Núcleo de Prática Jurídicas, cotejou-se a realidade verificada neste órgão dentro dos fins visados pela instituição curricular.

\section{A ESTRUTURAÇÃO DO ESTÁGIO SUPERVISIONADO NA HISTÓRIA DA METODOLOGIA DO ENSINO JURÍDICO}


Proclamada a independência da colônia brasileira em relação ao Reino Português, começa a germinar a inspiração da elite da nação incipiente que então nascia para que, por estas terras, fosse estabelecido um curso jurídico. A criação desse curso jurídico apresentava como objetivos a formação de homens para um dia tornarem-se magistrados ou advogados, bem como para a ocupação de cargos públicos, de deputados, senadores, diplomatas. Mencionado desiderato desembocava, portanto, na criação de uma cultura jurídica voltado para o atendimento de demandas acentuadamente burocráticas, o que se refletia em uma dogmática jurídica curricular fechada. Nesse sentido, de acordo com Wolkmer, as primeiras instituições de ensino jurídicos, "inspiradas em pressupostos formais de modelos alienígenas, contribuíram para elaborar um pensamento jurídico ilustrado, cosmopolita e literário, bem distante dos anseios de uma sociedade agrária da qual grande parte da população encontravase excluída e marginalizada". ${ }^{3}$

Nítida era a pretensão de romper com a tradição portuguesa na formação dos bacharéis em Direito. O Estado carecia de uma elite intelectual nacional, que consolidasse a emancipação do novo estado em relação as universidades europeias, sobretudo da escola de Coimbra. Neste contexto, são criados os primeiros cursos de direito, um em São Paulo e outro em Olinda, em 1827. Em 1854, por decreto, os cursos foram convertidos em Faculdades e o de Olinda fora transferido para Recife. Sobre isso, Sérgio Adorno pontua:

\begin{abstract}
A Academia de Direito de São Paulo, assim como a de Olinda, tem suas raízes atadas à independência política. Com a emergência do Estado Nacional, suscitou-se o delicado problema da autonomização cultural da sociedade brasileira, além da necessidade de formar quadros para o aparelho estatal. Nesse contexto, aos homens que haviam promovido e dirigido o curso da revolução descolonizadora não lhes parecia recomendável que essa sociedade se mantivesse dependente das universidades européias, sobretudo a de Coimbra. ${ }^{4}$
\end{abstract}

Historicamente, o curso de São Paulo - talvez devido a proximidade com a capital tornou-se centro formador de políticos ao passo que o curso de Direito de Olinda formou doutrinadores de renome.

Fixados os objetivos dos cursos jurídicos então criados, não causa estranheza, que o ensino apresentasse natureza muito conservadora, refletindo a ideologia jurídico-políticoeconômica do liberalismo, o que estabelecia um abismo intransponível entre os cursos de

\footnotetext{
${ }^{3}$ WOLKMER, Antônio Carlos. História do Direito no Brasil. 3. ed. Rio de Janeiro: Forense, 2002. p. 81.

${ }^{4}$ ADORNO, Sérgio. Os aprendizes do poder - o bacharelismo liberal na política brasileira. Rio de Janeiro: Paz e Terrra, 1988. p. 81.
} 
direito brasileiros e a visceral realidade da nação brasileira, permeada por necessidade sociais. Destarte, os cursos jurídicos voltam-se para a formação de profissionais técnicos, incapazes de desenvolver visão crítica do fenômeno jurídico, estruturado, portanto, por nefasto nefelibatismo utópico-literário. Tinhamos nessa fase inicial um ensino jurídico direcionado para as elites e sem vínculos com o povo, conforme aponta Wolkmer:

\begin{abstract}
Além disso, há que se fazer menção ao perfil dos bacharéis de Direito mediante alguns traços particulares e inconfundíveis. Ninguém melhor do que eles para usar e abusar do uso incontinente do palavreado pomposo, sofisticado e ritualístico. Não se pode deixar de chamar a atenção para o divórcio entre os reclamos mais imediatos das camadas populares do campo e das cidades e o proselitismo acrítico dos profissionais da lei que, valendo-se de um intelectualismo alienígeno, inspirado em princípios advindos da cultura inglesa, francesa ou alemã, ocultavam, sob o manto da neutralidade e da moderação política, a institucionalidade de um espaço marcado por privilégios econômicos e profundas desigualdades sociais. Na verdade, o perfil do bacharel juridicionista se constrói numa tradição pontilhada pela adesão ao conhecimento ornamental e ao cultivo da erudição lingüística. Essa postura, treinada no mais acabado formalisto retórico, soube reproduzir a primazia da segurança, da ordem e das liberdades individuais sobre qualquer outro princípio. ${ }^{5}$
\end{abstract}

Estas características iniciais do ensino jurídico, em virtude de sua qualificação congênita, se repetem atualmente, em uma realidade academia a partir da qual os cursos de direito continuam formando bacharéis para ocuparem cargos públicos e disseminar uma pressuposta ideologia predominante, que olvida segmentos populacionais sequiosos por justiça social.

Nos idos de 1961, pela lei $\mathrm{n}^{\circ} 4.024$ de 20 de dezembro, promulga-se o primeiro normativo acerca das diretrizes e bases da educação ${ }^{6}$, direcionada desde os níveis primário até os pós-graduação. A partir de mencionado normativo, institui-se o Conselho Federal de Educação, órgão que deteria atribuição para elaborar um currículo mínimo, imprescindível à própria qualificação como tais dos cursos pedagógicos.

Em 1962, o Conselho Federal de Educação cria o mencionado currículo mínimo para o Curso de Direito, fixando em cinco anos o interregno de duração regular do curso. Dentre as cadeiras não figura a de estágio supervisionado, mas somente disciplinas que incluíram prática forense, quais sejam, Direito Judiciário Civil (com Prática Forense) e Direito Judiciário Penal (com Prática Forense). A despeito disto, Gilmara Funes considera que "a prática forense estava presente sendo lecionada no conteúdo de Direito Judiciário,

\footnotetext{
${ }^{5}$ WOLKMER, ob. Cit., p. 99-100.

${ }^{6}$ Brasil. Lei n 4.024, de 20 de dezembro de 1961. Fixa as diretrizes e bases da educação nacional. Disponível em: <http://www.planalto.gov.br/ccivil_03/leis/L4024.htm> Acesso em 13 jul. 2016.
} 
demonstrando que em nenhum momento do histórico do currículo houve distanciamento com a disciplina de prática"7.

No auge da ditadura militar - e dotada de nítido caráter autoritário - é estabelecida a segunda Lei de Diretrizes e Base da Educação, mediante a edição da lei $5.540^{8}$ de 28 de novembro de 1968, cujo desiderato consistia na efetivação de uma reforma universitária. Sob sua vigência, instalou-se a concepção de que o ensino superior serviria a formação de profissionais, por meio de um ensino profissionalizante.

Posteriormente, por meio da resolução $n^{\circ} 03^{9}$ de 25 de fevereiro de 1972 do Conselho Federal de Educação, fixam-se novos parâmetros para o currículo mínimo do curso de direito. O grande mérito dessa resolução é dividir o currículo entre disciplinas básicas e profissionais, incluindo Prática Forense sob a forma de estágio supervisionado. Institui-se, portanto, a caracterização da prática jurídica como disciplina, passando esta a compor os currículos dos estudantes de direito.

Em 30 de dezembro de 1994, o Ministério da Educação edita a Portaria $n^{\circ} 1.886$, que revoga a resolução CFE no 03/72, tornando o Estágio de Prática Jurídica, supervisionado pela instituição de ensino superior, obrigatório e parte integrante do currículo.

Os Núcleos de Práticas Jurídicas restariam regulados por essa portaria pelos dez anos que a seguiriam, até o advento de ato da Câmara Educação Superior (CES), vinculada ao Conselho Nacional de Educação (CNE), que instituiria novas diretrizes curriculares para o curso de Direito. A Resolução CES/CNE nº 09, de 29 setembro de 2004, em vigor atualmente com as alterações em vias de efetivação, em virtude da aprovação do Parecer CNE/CSE $\mathrm{n}^{\mathrm{o}} 150^{10}$ em 5 de junho de 2013 , consolida a matéria referente ao estágio supervisionado

${ }^{7}$ FUNES, Gilmara Pesquero Fernandes Mohr. O estágio supervisionado e a formação prática dos aluno de direito. 162f, 2008. Dissertação (Mestrado em Educação) Universidade do Oeste Paulista - Presidente Prudente, 2008. p. 31.

${ }^{8}$ Brasil. Lei n 5.540 de 28 de novembro de 1968. Fixa normas de organização e funcionamento do ensino superior e sua articulação com a escola média, e dá outras providências. Disponível em <www.planalto.gov.br/ccivil_03/leis/L5540.htm> Acesso em 13 de jul. 2016.

${ }^{9}$ MINISTÉRIO DA EDUCAÇÃ̄O. Conselho Nacional de Educação. Diretrizes Curriculares - Cursos de Graduação. Disponível em <http://portal.mec.gov.br/conselho-nacional-de-educacao/atos-normativos-sumulas-pareceres-e-resolucoes?id=12991> Acesso em 13 jul. 2016.

${ }^{10}$ Há, atualmente, proposta de alteração de resolução, com parecer aprovado, que determina a nova redação para o preceptivo que trata sobre a matéria, alterando-a para os seguintes termos: Art. $7^{\circ} \mathrm{O}$ Estágio Supervisionado é componente curricular obrigatório, indispensável à consolidação dos desempenhos profissionais desejados, inerentes ao perfil do formando, devendo cada instituição, por seus colegiados próprios, aprovar o 
estabelecendo-o nos seguintes moldes:

Art. $7^{\circ} \mathrm{O}$ Estágio Supervisionado é componente curricular obrigatório, indispensável à consolidação dos desempenhos profissionais desejados, inerentes ao perfil do formando, devendo cada instituição, por seus colegiados próprios, aprovar o correspondente regulamento, com suas diferentes modalidades de operacionalização. $\S 1^{\circ} \mathrm{O}$ Estágio de que trata este artigo será realizado na própria instituição, através do Núcleo de Prática Jurídica, que deverá estar estruturado e operacionalizado de acordo com regulamentação própria, aprovada pelo conselho competente, podendo, em parte, contemplar convênios com outras entidades ou instituições e escritórios de advocacia; em serviços de assistência judiciária implantados na instituição, nos órgãos do Poder Judiciário, do Ministério Público e da Defensoria Pública ou ainda em departamentos jurídicos oficiais, importando, em qualquer caso, na supervisão das atividades e na elaboração de relatórios que deverão ser encaminhados à Coordenação de Estágio das IES , para a avaliação pertinente. $§ 2^{\circ}$ As atividades de Estágio poderão ser reprogramadas e reorientadas de acordo com os resultados teórico-práticos gradualmente revelados pelo aluno, na forma definida na regulamentação do Núcleo de Prática Jurídica, até que se possa considerá-lo concluído, resguardando, como padrão de qualidade, os domínios indispensáveis ao exercício das diversas carreiras contempladas pela formação jurídica.

Desta forma, o estágio supervisionado estabelece-se como disciplina obrigatória no currículo do curso de Direito, realizado na própria instituição de ensino superior, por meio dos Núcleos de Prática Jurídica, cuja estruturação pretende consolidar o perfil desejado para o formando. Materializa-se, portanto, como instrumento de ensino, distanciando o estágio supervisionado da prática rotineira realizada por instituições e empresas, nas quais o estágio profissional aproxima-se mais de uma prestação de serviços. A partir da qualificação hodiernamente visada, o estágio supervisionado, reestruturado curricularmente, possui por desiderato o fomento da habilidade de aquisição de conhecimento e da capacidade de refletir o direito de forma crítica.

correspondente regulamento, com suas diferentes modalidades de operacionalização. $\S 1^{\circ} \mathrm{O}$ estágio de que trata esse artigo poderá ser realizado: I - na própria Instituição de Educação Superior, por meio do seu Núcleo de Prática Jurídica, que deverá estar estruturado e operacionalizado de acordo com regulamentação própria, aprovada pelo seu órgão colegiado competente, podendo ser celebrado convênio com a Defensoria Pública para prestação de assistência jurídica suplementar; II - em serviços de assistência jurídica de responsabilidade da Instituição de Educação Superior por ela organizados, desenvolvidos e implantados; III - nos órgãos do Poder Judiciário, do Ministério Público, da Defensoria Pública e das Procuradorias e demais Departamentos Jurídicos Oficiais; IV - em escritórios e serviços de advocacia e consultorias jurídicas. $\S 2^{\circ}$ As atividades de Estágio Supervisionado poderão ser reprogramadas e reorientadas em função do aprendizado teórico-prático gradualmente demonstrado pelo aluno, na forma definida na regulamentação do Núcleo de Prática Jurídica, até que se possa considerá-lo concluído, resguardando, como padrão de qualidade, os domínios indispensáveis ao exercício das diversas carreiras contempladas pela formação jurídica. MINISTÉRIO DA EDUCAÇÃO. Conselho Nacional de Educação. Diretrizes Curriculares - Cursos de Graduação. Disponível em <http://portal.mec.gov.br/conselho-nacional-de-educacao/atos-normativos--sumulaspareceres-e-resolucoes?id=12991> Acesso em 13 jul. 2016. 


\section{ESTÁGIO SUPERVISIONADO NA FORMAÇÃO DO PERFIL DO ESTUDANTE DE DIREITO: APRIMORAMENTO DE COMPETÊNCIAS E HABILIDADES POR MEIO DA PRÁXIS}

Uma vez examinada a sua estruturação histórica, deveremos considerar os reflexos produzidos na formação do perfil do estudante de Direito que durante a sua graduação passa pelo Estágio Supervisionado.

Ressalte-se, inicialmente, que Horácio Rodrigues ${ }^{11}$, professor da Universidade Federal de Santa Catarina, critica a existência da dicotomia entre estágio curricular e extracurricular, concebendo que as atividades de estágio vinculam-se ao projeto educacional proposto pela instituição e, embora voltadas para a prática profissional, não podem esquecer o plano pedagógico. Outrossim, mencionadas instituições não podem olvidar que o estagiário é um estudante, aprendiz, que nas suas atividades é orientado, supervisionado por profissional com experiência, de forma que, semanticamente, somente se verifica a situação de estágio caso haja uma correlata supervisão. Apresenta ainda um conceito clarificante:

O estágio supervisionado se caracteriza por ser um conjunto de atividades práticas voltadas ao aprendizado e desenvolvimento das competências e habilidades atinentes às respectivas profissões, mas é necessariamente realizado em ambiente real e de forma supervisionada; ou seja, é inerente à natureza do estágio supervisionado que ele seja uma atividade prática, mas necessariamente desenvolvido em ambiente real e acompanhado de supervisão, pedagógica e profissional ${ }^{12}$.

$\mathrm{Na}$ disciplina de Estágio Supervisionado são desenvolvidas atividades de cunho eminentemente prático com vistas promover a "consolidação dos desempenhos profissionais desejados, inerentes ao perfil do formando", conforme estabelece a resolução CNE/CSE 09/2004 em seu art. $7^{\circ}$, caput. Sirlane Brüggmann aponta:

O estágio é o momento curricular em que a essência do ensino do Direito se concretiza, ou seja, é o momento em que a teoria cruza-se com a prática, é a experiência prática diuturna no exercício profissional e é a ação declarada de atitude, em que a teoria aprendida ao longo do curso efetiva-se, numa comunhão ${ }^{13}$.

\footnotetext{
${ }^{11}$ RODRIGUES, Horácio Wanderlei. Estágios e práticas simuladas: análise global e especificidades nos cursos de Direito. Seqüência: Estudos Jurídicos e Políticos, v. 28, n. 54, p. 199-210, 2007.

${ }^{12}$ Ibid., p. 201.

13 BRÜGGMANN, Sirlane de Fátima Melo. Estágio de prática jurídica como expressão do humanismo e instrumento transformador ao direcionamento da cidadania pluralista. 2009, 292f. Tese (Doutorado em Direito) Universidade Federal de Santa Catarina, Florianopólis, 2009. p. 149.
} 
Salutar reconhecer que o modelo tradicional de ensino do direito, formalista, legalista, promotor de uma ideologia liberal e distante da realidade social passa por crises que acabam por demonstrar sua inadequação. A forma como os Núcleos de Prática Jurídica são idealizados pode proporcionar mudanças de relevo na formação profissional, importando numa relação de ensino/aprendizagem mais humana, uma vez que aproxima os estagiários dos problemas sociais da vida comunitária.

Desta forma, o Núcleo de Prática de Jurídica, ao tempo em que proporciona a formação para o trabalho, promove no estagiário estudante de Direito o desenvolvimento da de sua formação humanista e de sua preparação para a cidadania, inserindo-o em atividades junto à comunidade, o que interfere substancialmente em sua formação profissional. Pontua Brüggmann que o Núcleo de Prática Jurídica:

(...) insere o estagiário nos problemas sociais da vida comunitária, prezando sempre pela ética como instrumento de aprimoramento humano e profissional, promovendo por meio do estágio, conforme já demonstrado, o seu comprometimento com o ensino-aprendizagem, com vistas a uma formação ética, crítica, criativa, transformadora, emancipatória, alicerçada em valores e instrumento de efetivação da cidadania pluralista ${ }^{14}$.

Como é cediço, o Direito comporta formas de solução de conflitos sociais e busca da paz social - talvez as principais. O estágio supervisionado ideal constitui aquele estruturado de forma a permitir que o futuro operador do Direito esteja preparado para apresentar soluções justas e pacificadoras, o que redunda em afastar a metodologia utilizada no ensino do Direito da empregada em cursos técnicos-profissionalizantes.

O Direito não pode ser concebido como mero curso profissionalizante, preparatório para o Exame da Ordem dos Advogados do Brasil ou para Concursos Públicos, e sim como o que está vocacionado a ser: curso com potencial crítico, humanístico e formador de profissionais com domínio integral dos conhecimentos precípuos às soluções para os problemas da sociedade. Neste aspecto Hironaka pontua:

Considerar que o Curso de Direito é curso de intenções só profissionalizante significa conceber que ele não precisa ser um curso superior: bastar-lhe-ia, para tanto, ser apenas um curso técnico, a exemplo dos cursos técnicos que equivalem,

${ }^{14}$ Ibid., p. 154. 
embora insuficientes ao ensino médio ${ }^{15}$.

A educação, conforme disposição constitucional expressa, "será promovida e incentivada com a colaboração da sociedade, visando ao pleno desenvolvimento da pessoa, seu preparo para o exercício da cidadania e sua qualificação para o trabalho" ${ }^{16}$. Com frequência relaciona-se as atividades desenvolvidas sob o Estágio Supervisionado com este último objetivo. Entretanto, considerando as características do Direito, convém compreender que o Estágio Supervisionado levado a cabo pelos Núcleos de práticas jurídicas deve promover esforços para que o estudante trilhe as três direções impostas pela Constituição. Vale mencionar, neste aspecto, os ensinamentos de Hironaka quanto à formação profissional do aluno do direito:

Nenhum profissional da área do Direito que seja incapaz de conceber soluções para os problemas sociais pode ser considerado um profissional adequado, justamente porque, dentre todas as carreiras ou profissões, o Direito é o único campo profissional que sempre tem consequências na estrutura da sociedade e na liberdade de todas as pessoas ${ }^{17}$.

Por óbvio que nem todos os alunos tem a inclinação para desenvolver plenamente o que o estágio supervisionado oferece, mormente no que diz respeito ao envolvimento com a sociedade, com a população carente, usuária frequente dos serviços ofertados pelos NPJ's. Não se ignora que muitos estudantes permanecem interesse constante apenas no que concerne à aquisição do diploma ou com a apreensão de conhecimentos práticos, o que, certamente, não pode servir de justificativa para que a instituição, o professor, o orientador ou o supervisor descuidem da formação complexa do estudante que envolva engajamento social, postura humanista e preparação para o trabalho.

\section{SUPERVISÃO: FUNÇÃO DO PROFESSOR ORIENTADOR NO DESENVOLVIMENTO DO ESTÁGIO}

\footnotetext{
${ }^{15}$ HIRONAKA, Giselda Maria Fernandes Novaes. Ensino jurídico no Brasil: desafios para o conteúdo de formação profissional. Anuário ABEDi, 2003. p. 52.

${ }^{16}$ BRASIL. Constituição (1988). Constituição da República Federativa do Brasil. Brasília, DF: Senado, 1988. Art. 205.

${ }^{17}$ HIRONAKA, Giselda Maria Fernandes Novaes. Op. Cit. p. 54.
} 
Respaldada sobre a necessidade de intermediação entre os saberes teoricamente apreendidos e a dinamicidade da realidade material, a função do Professor dedicado à orientação de alunos no Estágio Supervisionado qualifica-se como precípua para a consecução dos fins visados pela atividade curricular. Observe-se, a este teor, a natureza das atividades do professor orientador do Núcleo de Práticas Jurídicas da Universidade Federal do Ceará ${ }^{18}$ :

Art. $7^{\circ}$. - São atribuições dos Professores Orientadores:

I - prestar orientação e assistência aos estagiários no atendimento ao público e na elaboração das peças que fazem parte das atividades no NPJ;

II - controlar a assiduidade e verificar a eficiência dos estagiários;

III - cumprir os horários de expediente fixados pela Coordenação do NPJ;

IV - entregar relatório trimestral à Coordenação do NPJ sobre das atividades desenvolvidas pelos estagiários pelos quais estejam responsáveis;

$\mathrm{V}$ - avaliar os relatórios exigidos aos estagiários, controlando as respectivas entregas;

VI - transmitir instruções e ensinamentos práticos aos estagiários, com a finalidade de propiciar-lhes uma aprendizagem dos aspectos gerais das funções dos operadores do Direito, inclusive procedimentos éticos;

VII - controlar o prazo máximo de até 10 (dez) dias para finalização de atendimentos e de até 7 (sete) dias para elaboração da petição inicial para encaminhamento à Defensoria Pública para efetivo início do processo;

VIII - orientar os estagiários na elaboração das petições, supervisionando e avaliando sua correta e tempestiva elaboração;

IX - fiscalizar os documentos recebidos do público assistido e verificar se está adequada e suficiente para o ajuizamento da ação;

$\mathrm{X}$ - sugerir à Coordenação do NPJ propostas de programas a serem desenvolvidos no estágio, como cursos de extensão, projetos de pesquisa jurídica, seminários e outros;

XI - desempenhar outras atividades inerentes às suas atribuições, como visitas, palestras, cursos e outros;

\footnotetext{
${ }^{18}$ Ressalte-se, ainda, que a Portaria $n^{\circ} 02$ de 13 de janeiro de 2015 da Coordenadoria do Núcleo de Práticas Jurídicas da Universidade Federal do Ceará estabelece, em seu artigo $8^{\circ}$ : Sem prejuízo de outras atribuições que lhe sejam cometidas pela Coordenação do NPJ, cada professor-orientador ficará sujeito às seguintes regras: I Comparecer à reunião com a Coordenação do NPJ, antes do início do atendimento, em cada semestre letivo, cuja data e horário serão previamente informados; II - Atender as disposições da presente portaria, acompanhando e orientando os alunos que estiverem sob sua orientação quanto ao seu cumprimento; III - Disponibilizar aos alunos os meios necessários à comunicação bilateral, especialmente o seu endereço eletrônico (email), de modo a facilitar a execução das atividades do Núcleo; IV - Apresentar aos alunos, em reunião previamente designada, o plano de atividades, o qual deverá contemplar os objetivos pedagógicos do NPJ, orientações gerais, as atividades presenciais, além da sistemática e critérios de avaliação; V - Cumprir escalas de horários internos de supervisão presencial dos atendimentos, a ser posteriormente divulgada pelo Núcleo, cabendo ao docente informar, com antecipação, à Secretária de eventual falta e de quem o substituirá na oportunidade; VI - Finalizar, até o fim do período de atividades do NPJ, todos os atendimentos e processos de responsabilidade dos alunos lotados em sua turma, acompanhando o fluxo administrativo dos processos sob seu controle e supervisão e exigindo o cumprimento das responsabilidades discentes quanto à realização de atos ou elaboração de documentos necessários à protocolização judicial ou administrativa; VIII - Informar à Secretaria, através do e-mail npj@ufc.br, as notas de cada aluno componente de sua turma dentro dos prazos próprios do Núcleo, ciente da obrigação de somente divulgá-las aos alunos após liberação da Secretaria, que analisará os outros quesitos necessários à aprovação na Atividade (faltas e pendências administrativas), em atendimento à sistemática do NPJ e ao Calendário Acadêmico da Universidade, especialmente o período imediatamente anterior às solenidades de conclusão do Curso e Colaçao de Grau e as tarefas administrativas que o compõe. Disponível em: <http://www.direito.ufc.br/images/stories/imagens/portarias.pdf> Acesso em: 12 jul. 2016.
} 
XII - avaliar os alunos, ao final de cada semestre, decidindo por sua aprovação, ou não, na disciplina Estágio Supervisionado, considerando freqüência, desempenho e relatórios apresentados. ${ }^{19}$

Nesse sentido, conforme se depreende da análise das incumbências deferidas, o docente orientador compõe o arcabouço basilar de uma Universidade que, conforme ensinamento de Roberto Aguiar, almeja “construir instrumentais que propiciem um aumento de consciência de seus discentes, a fim de que eles sejam minimamente aptos para entender o contexto onde vão operar e o sentido de sua ação no mundo"20.

Em verdade, a letra fria comportada na norma jurídica não prescinde de um leitura perpetrada por um olhar humanista, de sorte que a incumbência do docente responsável pela supervisão advém de uma exigência social, relacionada a indicação não apenas dos caminhos interpretativos, mas também da tenacidade do caminhar. Nesse sentido, desconstrói-se o paradigma da construção tradicional do conhecimento, segundo a qual o estudante, tabula rasa, desprovido de quaisquer conceitos, representa um papel passivo no cenário da aprendizagem. Tal seria o conceito típico ao sistema bancário de educação, segundo o qual o professor deposita conceitos no discente, almejando auferir ipsis litteris citadas definições em avaliações metodologicamente fechadas. Nesse sentido, aduz Paulo Freire:

A narração, de que o educador é o sujeito, conduz os educandos à memorização mecânica do conteúdo narrado. Mais ainda, a narração os transforma em 'vasilhas', em recipiente a serem 'enchidos' pelo educador. Quanto mais vá enchendo os recipientes com seus 'depósitos', tanto melhor educador será. Quanto mais se deixem totalmente 'encher' tanto melhores educandos serão. ${ }^{21}$

A metodologia tradicional de transmissão de saberes alicerça-se sobre a percepção de que os conteúdos jurídicos devem ser compreendidos teoricamente, porquanto a realidade prática consista na mera subsunção do abstrato para o material. Desta forma, o papel do estudante, futuro aplicador do direito, resumir-se-ia à mera identificação dos preceptivos legais que narram a situação cotejada, bem como suas consequências normativas.

19 Regulamento do Núcleo de Práticas Jurídicas da Universidade Federal do Ceará. Disponível em: <http://www.direito.ufc.br/images/stories/arquivos/npj\%20regulamento\%20-\%2025nov2010.2.pdf> Acesso em: 12 jul 2016.

20 Aguiar, Roberto A. R. de. A Contemporaneidade e o Perfil do Advogado. Brasília: Novas Diretrizes Curriculares, 1996. p. 129-141.

${ }^{21}$ FREIRE, Paulo. Pedagogia do oprimido. 38. ed. São Paulo: Paz e Terra. 2002. p. 66. 
A partir da reestruturação do ensino, fundamentada pela quebra do paradigma da simplificação ${ }^{22}$, conforme aponta Edgar Morin, restou impossível manter, dentro da metodologia do ensino jurídico o esquema cartesiano de ensino, de sorte que uma visão humanitária, menos motivada para a "redução do outro" e mais direcionada para a "pertença ao mundo", constitui uma demanda para os olhos jurídicos do estudante de direito do atual cenário mundial, permeado pela complexidade. Nesse sentido, aponta o autor:

Conhecer o nosso planeta é difícil: os processos de todas as ordens, econômicos,
ideológicos, sociais estão de tal maneira imbricados e são tão complexos que é um
verdadeiro desafio para o conhecimento. Já é difícil saber o que acontece no plano
imediato. Ortega y Gasset dizia: "Não sabemos o que acontece, isto é o que
acontece", é necessário uma certa distância em relação ao imediato para poder
compreende-lo e atualmente em que tudo é acelerado e tudo é complexo, é quase
impossível. Mas, é preciso mostrar, é esta a dificuldade; é necessário ensinar que
não é suficiente reduzir a um só a complexidade dos problemas importantes do
planeta como a demografia, ou a escassez de alimentos, ou a bomba atômica ou a
ecologia. ${ }^{23}$

Nesse panorama, o tradicionalismo epistemológico exigiria do professor orientador, mesmo durante a aplicação prática dos conceitos apreendidos, uma priorização da "inteligência parcelar, compartimentada, mecânica, disjuntiva, reducionista" ${ }^{24}$, que não fornecia ao estudante de direito uma noção eficaz acerca da complexidade advinda da práxis jurídica. Esta pedagogia da fragmentação do saber precariza fundamentalmente a formação do estudante de direito, empobrecendo a construção profissional do discente, uma vez que "sufoca a sua capacidade de pensamento autônomo, de pensar com a própria cabeça e de se posicionar criticamente diante da realidade e do próprio conteúdo desse ensino."25

A partir da instituição de um novo paradigma de complexidade, no qual a fragmentação do conhecimento não mais fornece as habilidades profissionais adequadas ao jurista, o aluno não deve quedar frustrado em seu desiderato de aprender. Em verdade, o modo de construção do saber é reinventado, exercendo o professor papel essencial neste cenário de pedagogia da autonomia, no qual "experiências estimuladoras da decisão e da

\footnotetext{
22 De acordo com Morin, o Paradigma da Simplificação impõe que os conteúdos sejam disjuntos e reduzidos, sem qualquer necessidade de uma teia de complexidade entre as diferentes disciplinas. Cf. MORIN, Edgar; LE MOIGNE, Jean-Louis. A Inteligência da Complexidade. São Paulo: Petrópolis, 2000.

${ }^{23}$ MORIN, Edgar. Os sete saberes necessários à educação do futuro. São Paulo: Cortez; 2000.

${ }^{24}$ MORIN, Edgar. Da necessidade de um pensamento complexo. In: Francisco Menezes Martins e Juremir Machado da Silva (org). Para navegar no século XXI. Porto Alegre: Sulina/Edipucrs. 2000.

${ }^{25}$ MARQUES NETO, Agostinho Ramalho. Reflexões sobre o ensino de Direito. In: Anais Seminário Nacional de Ensino Jurídico, Cidadania e Mercado de Trabalho. Curitiba: Gráfica Linarth, 1996. p. 30.
} 
responsabilidade" 26 amoldam a própria emancipação do estudante de direito. Há, neste panorama, uma ideia de fomento da independência do estudante de direito, que não mais quedará aturdido ao perceber a inexistência patente de subsunção entre a realidade complexa e a simples prescrição normativa.

No reconhecimento do complexo, o professor não cria a independência - de fato, tal “criação" seria mesmo fíctícia, porquanto orquestrada heteronimicamente -, mas sim constrói, junto com o discente, soluções para as problemáticas cotidianas da realidade dinâmica. Aponta Hargreaves:

Quando os professores trabalham para promover a independência do aluno, estão realmente os ensinando a serem responsáveis pelo próprio aprendizado e dando-lhes as ferramentas para assumirem isso com equilíbrio e com segurança. As estratégias mais efetivas para aumentar a motivação estão ligadas a tratar os alunos como pessoas capazes, tornar o material relevante valorizando o conhecimento e os interesses dos alunos e envolvê-los na determinação dos objetivos, nos métodos de aprendizado e nos critérios para o sucesso. Quando os alunos são participantes ativos no próprio aprendizado e na auto-avaliação, aumentam sua autoconsciência e começam a compreender erros, problemas difíceis e mesmo fracassos como parte natural do aprendizado e da vida real. ${ }^{27}$

A função de supervisão efetivada pelo professor orientador do estágio supervisionado estrutura-se, portanto, de maneira horizontal, uma vez que a este cabe guiar, e não ditar, o processo de aprimoramento da prática do estudante de direito. Muito mais do que simplesmente fiscalizar e avaliar, ao docente incumbe viabilizar o conhecimento dialógico, o qual deve ser protagonizado pelo próprio aluno, que configurará o futuro profissional de direito.

Neste desiderato, sobreleva ainda a necessidade de fomentar o espírito crítico dos estudantes de direito, na medida em que sua conformação ao que resta posto normativofaticamente explicita uma incapacidade de incorporação do papel de atores sociais ativos. Esta participação positiva e transformadora floresce em um panorama no qual o estudante em formação constrói uma consciência que percebe a realidade não como um dado posto, mas sim como um substrato sobre sua emancipação pode agir. Conforme prelecionado por Adorno, há, na educação voltada para uma consciência emancipada, uma possibilidade para

\footnotetext{
${ }^{26}$ FREIRE, Paulo. Pedagogia da autonomia: saberes necessários à pratica educativa. São Paulo: Paz e Terra, 2002.

${ }^{27}$ HARGREAVES, Andy; EARL, Lorna; RYAN, Jim. Educação para a mudança. Porto Alegre: Artmed Editora, 2001. p. 193.
} 
que o aluno se desenvolva socialmente, mormente por meio da constituição de uma "autoreflexão crítica" 28 .

Deste modo, a orientação no tocante à "redação de peças processuais e profissionais, rotinas processuais, assistência e atuação em audiências e sessões, vistas a órgãos judiciários, prestação de serviços jurídicos e técnicas de negociações coletivas, arbitragens e conciliação"29 efetiva-se em um panorama de expressão dos saberes apreendidos teoricamente, em face da abordagem de situações reais. $\mathrm{O}$ acúmulo qualitativo de experiência obtido no desenrolar destas atividades deve permear a formação da consciência crítica emancipada, em um processo mediado pelo professor orientador.

Ressalte-se, ainda, que, na implementação desta mentoriação, o professor orientador deve possuir o perfil adequado para tanto, de sorte que a práxis jurídica deve compor a sua própria formação. Explicitando tal demanda, Fincato estabelece:

Para que tal intenção se concretize, também é necessário, sem dúvida, um perfil docente adequado, principalmente quando se fala em prática jurídica. Seus professores devem necessariamente exercer o direito, notoriamente a advocacia. $\mathrm{Na}$ direção e supervisão das atividades de prática jurídica, admitem-se apenas professores com inscrição ativa na Ordem dos Advogados do Brasil. O professor, para ministrar sua disciplina, além de conhecer o direito material a que ela está vinculado, deve demonstrar conhecimentos elevados de direito processual, assim como de estrutura judiciária. Para além disso, deve transpirar o compromisso que decorre de sua função social, o que o afasta do modelo tradicional das aulas jurídicas (obrigando-o à recomposição de métodos, técnicas e até - por que não? - de suas próprias ideologias). ${ }^{30}$

Nada obstante, não é incomum que a orientação efetivada no Estágio Supervisionado, a despeito de idealizada com fins nobres, desemboque em uma maquiagem na formação precária do aluno. Com efeito, não se ignora que professores sem prática jurídica quedam por efetivar atividades de supervisão pautados em modelos e formulários préformulados, sem observar os objetivos visados teleologicamente por este eixo curricular.

A constatação de pactos de mediocridade, em face dos quais o professor dissimula a supervisão e o aluno finge ser orientado, mormente no que concerne ao estágio

\footnotetext{
${ }^{28}$ ADORNO, Theodor W. Educação e emancipação. 3. ed. Tradução de Wolfgang Leo Maar. São Paulo: Paz e Terra, 2003. p. 121.

${ }^{29}$ Artigo 11 da Portaria $\mathrm{n}^{\circ} 1.886$ de 1994, que fixa as diretrizes curriculares e o conteúdo mínimo do curso jurídico. Disponível em: <http://oab-rn.org.br/arquivos/LegislacaosobreEnsinoJuridico.pdf> Acesso em: 12 jul. 2016.

${ }^{30}$ FINCATO, Denise Pires. Estágio de docência, prática jurídica e distribuição da justiça. Revista Direito GV, v. 6, n. 1, p. 029-037. 2010.
} 
supervisionado, deve ser o primeiro passo para a modificação da metodologia de ensino vitrine, com vista a que "a prática forense realmente seja prática. Só assim os bacharéis em direito poderão aspirar um conhecimento menos sofrível." ${ }^{31}$.

Neste sentido, o ato pedagógico perpetrado pelo professor orientador responsável por supervisionar o estágio curricular, voltado para efetivamente fomentar a consciência crítica emancipada, constitui sobretudo um ato de amor à pedagogia e docência transformadoras, em virtude das quais professor e aluno, restam aptos a construir "uma sociedade com melhores chances de todos os homens serem felizes." 32

\section{EXPERIÊNCIA DO NÚCLEO DE PRÁTICAS JURÍDICAS DA FACULDADE DE DIREITO DA UNIVERSIDADE FEDERAL DO CEARÁ}

Porquanto a realidade institucional de cada universidade reste permeada por peculiaridades locais, a análise da efetividade prática geral do estabelecimento curricular do Estágio Supervisionado queda dificultada, mormente considerando a priorização das consequências qualitativas de formação de profissionais. Neste sentido, escapa às médias aritméticas a consecução de um balanço pormenorizado sobre os efeitos advindos da atividade em todos os centros universitários do país.

Em virtude disto, cumpre observar, para cotejar a temática, de que forma se estrutura, dentro do quadro da Faculdade de Direito da Universidade Federal do Ceará, o Núcleo de Práticas Jurídicas, setor responsável por concentrar, nesta entidade educacional, as atividades conexas ao estágio supervisionado.No seio do Centro Clóvis Beviláqua, a atividade de estágio supervisionado articula-se em dois eixos, que constituem disciplinas curriculares obrigatórias: Prática Jurídica I (referente à aplicação simulada dos conceitos teóricos) e Prática Jurídica II (relacionada à assistência jurídica real prestada).

Ao aluno resta possibilitado, nestas disciplinas "integrar os conhecimentos jurídicos, teóricos e práticos adquiridos no transcorrer do curso, prestando assistência jurídica gratuita comunidade considerada carente" 33 . Denota-se, portanto, o papel efetivado por este setor na

\footnotetext{
${ }^{31}$ FERREIRA SOBRINHO, José Wilson. Didática e aula em Direito. Porto Alegre: Sérgio Antonio Fabris, 2000. p. 70.

${ }^{32}$ GADOTTI, Moacir. Pedagogia da práxis.. 2 ed. São Paulo: Cortez. 1998. p. 81.

33 Regulamento do Núcleo de Práticas Jurídicas da Universidade Federal do Ceará. Disponível em: $<\mathrm{http}: / /$ www.direito.ufc.br/images/stories/arquivos/npj\%20regulamento\%20-\%2025nov2010.2.pdf $>$ Acesso em: 12 jul 2016.
} 
promoção da identidade entre o aluno que sabe a lei e o profissional que aplica a lei, em observância de uma consciência humanista e crítica, que percebe a complexidade dinâmica do meio.

$\mathrm{Na}$ efetivação dos desideratos visados, a estruturação de um corpo funcional resta precípua, em face do que, de acordo com o Regulamento Geral do Núcleo de Práticas, restam estabelecidos uma Coordenadoria e uma Secretaria Administrativa. Compõe este organograma um coordenador, eleito por colegiado, cujo mandato tem duração de dois anos, admitida uma recondução; um servidor de qualificação de nível médio; e demais servidores com formação em Direito e inscrição na Ordem dos Advogados do Brasil, submetidos à regime de 6 (seis) horas ininterruptas.

O Núcleo de Práticas Jurídicas da UFC efetiva suas atividades de forma conveniada com a Defensoria Pública do Estado do Ceará, priorizando os termos estabelecidos no Artigo $7^{\circ}$ da Resolução CNE/CES no 9/2004, desde fevereiro de 2012. Ressalte-se que a Defensoria Pública do Estado do Ceará cumpre a função prevista no artigo $5^{\circ}$, LXXIV da Constituição Federal, restando, portanto, incumbida da prestação de orientação jurídica e de promover a defesa dos necessitados. Nesse sentido, a Lei Complementar nº 06/1997 do Estado do Ceará estabelece:

\footnotetext{
Art. $2^{\circ}$. A Defensoria Pública é instituição essencial à função jurisdicional do Estado, incumbindo-lhe prestar gratuita e integral assistência jurídica, judicial e extrajudicial, aos necessitados, compreendendo a orientação, postulação e defesa de seus direitos e interesses, em todos os graus e instâncias, compreendido entre estes, o juízo das pequenas causas, na forma do inciso LXXIV, do Art. $5^{\circ}$, da Constituição Federal. $\S 1^{\circ}$. Considera-se juridicamente necessitado, o declaradamente pobre na forma da lei.

$\S 2^{\circ}$. À Defensoria Pública é conferido o direito de apurar o estado de carência dos seus assistidos.

$\S 3^{\circ}$. Na gratuidade da assistência jurídica aos necessitados, de que trata o caput deste artigo, incluem-se a proibição de cobranças de taxas, emolumentos ou depósitos judiciais, ou outras cobranças de qualquer tipo ou natureza. ${ }^{34}$
}

A instituição estadual possui convênio firmado com 11 universidades, nas quais funcionam núcleos de práticas jurídicas. No que concerne à Faculdade de Direito da UFC, mencionado ajuste não inclui todas as competências albergadas pela DPE/CE, em virtude de

\footnotetext{
${ }^{34}$ Disponível em: <http://www.al.ce.gov.br/legislativo/ementario/lc06.htm> Acesso em: 13 jul. 2016.
} 
questões logísticas de alta complexidade, inerentes a determinadas situações fáticonormativas, mormente aquelas tratadas na seara penalista. De acordo, ainda, com o termo do convênio firmado, com validade até 31 de dezembro de 2017, são finalidades da parceria estabelecida:

I - Promover a formação prático-teórica do corpo discente da instituição de ensino superior;

II - Propiciar aos alunos conhecimento das atividades desenvolvidas pela Defensoria Pública;

III - Prestar orientação jurídica e elaborar procedimentos necessários, de forma gratuita, para os hipossuficientes. ${ }^{35}$

Cumpre ressaltar que, desde nove de abril de 2012 até maio de 2014, foram realizados 775 atendimentos pelos alunos matriculados na Disciplina de Prática Jurídica II, abordando questões relacionadas a Divórcio (consensual e litigioso), a Alimentos (gravídicos, consensuais e litigiosos) e a Usucapião. A partir do contato com o modus operandis da instituição, cujo caráter assistencialista e humanitário denota uma preocupação com a efetivação da justiça social, o estudante de Direito da UFC, curso corriqueiramente taxado como exclusividade de uma casta elitizada, têm a oportunidade de entrar contato com realidades até então ignoradas. Tal parceria enseja a efetivação daquilo que Rui Barbosa alcunhou de "função da cultura jurídica", qual seja a "formação de um sentimento de justiça"36.

Apesar de não contar com serviços de Assistência Social e Psicologia, geralmente presentes em outras instituições, o Núcleo de Práticas Jurídica da UFC esmera-se em firmar um diálogo com os demais projetos de extensão da faculdade, tais como o Arvore-ser (Grupo de Estudos Aplicados em Direito das Pessoas com Deficiência) e o Dialogar. Destarte, os alunos têm contato direto com diversas demandas relacionadas à realidade das Pessoas com Deficiência, em um cenário particular, no qual os debates acerca da recente Lei Brasileira de Inclusão suscitam questionamentos acerca da aplicação dos preceptivos constantes no diploma. Ressaltando, nesse sentido, o papel da diversidade na formação do humanista brasileiro, aponta Aranha:

Não há modelos prontos, nem receitas em manuais. A sociedade brasileira ainda precisa tornar sua prática consistente com seu discurso legal. Há que buscar soluções para a convivência na diversidade que a caracteriza, enriquece, dá sentido e

\footnotetext{
${ }^{35}$ Informações fornecidas pela Secretaria do Núcleo de práticas jurídicas da Universidade Federal do Ceará.

${ }^{36}$ BARBOSA, RUI. Obras Completas de Rui Barbosa. V. 36. t. 1. 1909. p. 221
} 
significado. Há que efetivamente favorecer a convivência e a familiaridade com as pessoas com deficiência, derrubando as barreiras físicas, sociais, psicológicas e instrumentais que as impede de circular no espaço comum. ${ }^{37}$

Além disso, a parceria firmada com o Dialogar, projeto de extensão sobre mediação e conciliação, lapida a visão do estudante, acostumado à belicosidade do litígio, tão ressaltada doutrinariamente. Sobre o papel destes mecanismos extrajudiciais de resolução de conflitos, cumpre ressaltar o entendimento de Coutinho e Reis:

\begin{abstract}
Nesta forma de solucionar conflitos não existirá vencidos ou vencedores, mas uma solução que seja satisfatória às duas partes. Desta forma, nasce a possibilidade de desenvolvimento de reformulação das questões corriqueiras a que todos estamos sujeitos - as quais influenciam direta ou indiretamente nas relações interpessoais - e, então, passa-se a construir relações pautadas no diálogo, logo a relação adversarial passa a ocupar cada vez menos espaço. ${ }^{38}$
\end{abstract}

Portanto, veja-se que, apesar das carências estruturais e organizacionais, a instituição esmera-se em lapidar a formação humanista de uma consciência discente crítica, emancipada do texto da lei apático. O funcionamento Núcleo de Prática Jurídicas da Faculdade de Direito da Universidade Federal do Ceará reflete, nesse sentido, os fins visados pela instituição curricular obrigatória, qual seja a aproximação dos alunos de direito da realidade prática que os cerca.

\title{
6 CONCLUSÃO
}

A partir do estudo realizado, inferiu-se que a contribuição do Estágio Supervisionado para a formação do profissional de direito compõe a própria matriz humanista inerente idealmente - a cursos jurídicos voltados para a emancipação, para a autonomia e para a consecução da justiça social. Neste sentido, partindo do pressuposto de que o perfil esperado do discente jurídico envolve um desenvolvimento humano irrenunciável, o Estágio Supervisionado, ao fomentar o contato do estudante de direito com o meio, é, teleologicamente, essencial à estruturação do processo de formação do futuro jurista.

Destarte, uma vez que a cultura atual do bacharelado pressupõe, cada vez mais, que a formação de juristas não prescinde da formação de humanistas, que tenham habilidade para o

\footnotetext{
${ }^{37}$ ARANHA, Maria Salete Fábio. Paradigmas da relação da sociedade com as pessoas com deficiência. Revista do Ministério Público do Trabalho, v. 11, n. 21, p. 160-173, 2001.

${ }^{38}$ COUTINHO, Patrícia Martins Rodrigues; REIS, Marcos Aurélio. A prática da mediação e o acesso à justiça: por um agir comunicativo. TJDFT. 2010. Disponível em: <http://www.tjdft.jus.br/trib/vij/docVij/artigos/AR TIGOCIENTIFICO_MEDIACAOUNIEURO.pdf >. Acesso em: 13 jul. 2016.
} 
trato social, aptidão esta que não emerge da leitura de textos e normas, o Estágio Supervisionado cumpre papel de emancipação e de fomento da autonomia do estudante de direito.

Ao possibilitar um sopesamento axiológico-fático, perpetrado pelo próprio discente, a atividade praticada permite que se desprenda do léxico ideal sua tonalidade real - sempre tão dinâmica e fluida. No desenvolvimento destas aptidões, a figura do professor orientador cumpre a função de fazer pulsar as veias do espírito crítico de uma mente emancipada.

\section{REFERÊNCIAS}

ADORNO, Sérgio. Os aprendizes do poder - o bacharelismo liberal na política brasileira. Rio de Janeiro: Paz e Terrra, 1988.

ADORNO, Theodor W. Educação e emancipação. 3. ed. Tradução de Wolfgang Leo Maar. São Paulo: Paz e Terra, 2003.

AGUiAR, Roberto A. R. de. A Contemporaneidade e o Perfil do Advogado. Brasília: Novas Diretrizes Curriculares, 1996.

ARANHA, Maria Salete Fábio. Paradigmas da relação da sociedade com as pessoas com deficiência. Revista do Ministério Público do Trabalho, v. 11, n. 21, p. 160-173, 2001.

BRASIL. Constituição (1988). Constituição da República Federativa do Brasil. Brasília, DF: Senado, 1988.

BRÜGGMANN, Sirlane de Fátima Melo. Estágio de prática jurídica como expressão do humanismo e instrumento transformador ao direcionamento da cidadania pluralista. 2009, 292f. Tese (Doutorado em Direito) Universidade Federal de Santa Catarina, Florianopólis, 2009.

COUTINHO, Patrícia Martins Rodrigues; REIS, Marcos Aurélio. A prática da mediação e o acesso à justiça: por um agir comunicativo. TJDFT. 2010. Disponível em: <http://www.tjdft.jus.br/trib/vij/docVij/artigos/AR

TIGOCIENTIFICO_MEDIACAOUNIEURO.pdf >. Acesso em: 13 jul. 2016.

FERREIRA SOBRINHO, José Wilson. Didática e aula em Direito. Porto Alegre: Sérgio Antonio Fabris, 2000.

FINCATO, Denise Pires. Estágio de docência, prática jurídica e distribuição da justiça. Revista Direito GV, v. 6, n. 1, p. 029-037. 2010.

FREIRE, Paulo. Pedagogia do oprimido. 38. ed. São Paulo: Paz e Terra. 2002. 
FREIRE, Paulo. Pedagogia da autonomia: saberes necessários à pratica educativa. São Paulo: Paz e Terra, 2002.

FUNES, Gilmara Pesquero Fernandes Mohr. O estágio supervisionado e a formação prática dos aluno de direito. 162f, 2008. Dissertação (Mestrado em Educação) Universidade do Oeste Paulista - Presidente Prudente, 2008.

GADOTTI, Moacir. Pedagogia da práxis.. 2 ed. São Paulo: Cortez. 1998

GHIRARDI, José Garcia; FEFERBAUM, Marina. Ensino do direito em debate: reflexões a partir do $1^{\circ}$ Seminário Ensino Jurídico e Formação Docente. São Paulo: Direito GV, 2013.

HARGREAVES, Andy; EARL, Lorna; RYAN, Jim. Educação para a mudança. Porto Alegre: Artmed Editora, 2001. p. 193.

HIRONAKA, Giselda Maria Fernandes Novaes. Ensino jurídico no Brasil: desafios para o conteúdo de formação profissional. Anuário ABEDi, p. 41-62, 2003.

MARQUES NETO, Agostinho Ramalho. Reflexões sobre o ensino de Direito. In: Anais Seminário Nacional de Ensino Jurídico, Cidadania e Mercado de Trabalho. Curitiba: Gráfica Linarth, 1996.

MORIN, Edgar. Da necessidade de um pensamento complexo. In: Francisco Menezes Martins e Juremir Machado da Silva (org). Para navegar no século XXI. Porto Alegre: Sulina/Edipucrs. 2000.

MORIN, Edgar. Os sete saberes necessários à educação do futuro. São Paulo: Cortez; 2000.

MORIN, Edgar; LE MOIGNE, Jean-Louis. A Inteligência da Complexidade. São Paulo: Petrópolis, 2000.

RODRIGUES, Horácio Wanderlei. Estágios e práticas simuladas: análise global e especificidades nos cursos de Direito. Seqüência: Estudos Jurídicos e Políticos, v. 28, n. 54, p. 199-210, 2007

RODRIGUES, Horácio Wanderlei. Novo currículo mínimo dos cursos jurídicos. São Paulo: Revista dos Tribunais, 1995

WOLKMER, Antônio Carlos. História do Direito no Brasil. 3. ed. Rio de Janeiro: Forense, 2002. 